\title{
Allele-Specific Oligonucleotide
}

National Cancer Institute

\section{Source}

National Cancer Institute. Allele-Specific Oligonucleotide. NCI Thesaurus. Code C127881.

An oligonucleotide designed to be specific for only one allele of a gene. 